\title{
O SUS na vida dos brasileiros: assistência, acessibilidade e equidade no cotidiano de usuários da Atenção Primária à Saúde
}

\author{
I ${ }^{1}$ Leila Cristine do Nascimento, ${ }^{2}$ Selma Maria da Fonseca Viegas, ${ }^{3}$ Cássia Menezes, \\ ${ }^{4}$ Gabriel Rios Roquini, 5 Thiago Rocha Santos I
}

Resumo: Objetivo: compreender a assistência à saúde, equidade e acessibilidade no cotidiano de usuários da Atenção Primária à Saúde (APS). Metodologia: trata-se de um estudo qualitativo e descritivo, delineado pelo método de Estudo de Casos Múltiplos Holístico e pelo referencial teórico da Sociologia Compreensiva do Cotidiano.

Participaram 77 usuários do SUS (Sistema Único de Saúde) de dois municípios de Minas Gerais, Brasil. Resultados: foram identificadas a noção do usuário sobre o SUS, sua idealização, a realidade vivida considerando a acessibilidade e a assistência na APS, relacionando-as com o direito à saúde. Conclusóes: a APS ainda enfrenta dificuldades para efetivamente ser a porta de entrada preferencial nas realidades estudadas. Observam-se limites de estrutura na APS para alcançar a assistência integral em rede. A superação de dificuldades e limites é central para o fortalecimento do SUS.

> Palavras-chave: acesso aos serviços de saúde; assistência à saúde; equidade em saúde; atenção primária à saúde; Sistema Único de Saúde.

\author{
1 Universidade Federal de São \\ João del-Rei. Divinópolis-MG, \\ Brasil (leilacnasc@gmail.com). \\ ORCID: 0000-0003-4744-4576 \\ ${ }^{2}$ Universidade Federal de São \\ João del-Rei. Divinópolis-MG, \\ Brasil (selmaviegas@ufsj.edu.br) \\ ORCID: 0000-0002-0287-4997 \\ ${ }^{3}$ Universidade Federal de São João \\ del-Rei. Divinópolis-MG, Brasil \\ (menezescassia7@gmail.com). \\ ORCID: 0000-0001-9218-4668 \\ ${ }^{4}$ Universidade Federal de São \\ João del-Rei. Divinópolis-MG, \\ Brasil (gabriel199704@gmail.com). \\ ORCID: 0000-0002-4146-5520 \\ ${ }^{5}$ Universidade Federal de São João \\ del-Rei. Divinópolis-MG, Brasil \\ (thiagorocha.bh@gmail.com). \\ ORCID: 0000-0002-4635-3421
}

Recebido em: 24/03/2020 Aprovado em: 28/07/2020 Revisado em: 10/09/2020 


\section{Introdução}

A Constituição da República Federativa do Brasil de 1988 estabeleceu o direito à saúde de forma universal e integral, a ser garantida pelo Estado (BRASIL, 1988). Nessa Constituição, foi estabelecida a criação do Sistema Único de Saúde (SUS) como sistema público de acesso universal, integral e equânime. Por conseguinte, o SUS inova a gestão pública ao trazer o controle social para as suas bases, com a constante pactuação de metas, juntamente à população, representando um relevante ganho em política, democracia e participação social (PESSOTO; RIBEIRO; GUIMARÃES, 2015; FREITAS; ARAÚJO, 2018).

Trata-se, sobretudo, de um sistema complexo, responsável pela articulação e coordenação das açôes de prevenção de agravos, de promoção e reabilitação da saúde. Contudo, é um desafio, especialmente para os formuladores de políticas públicas, garantir a disponibilidade e a acessibilidade à saúde para toda a população (OLIVEIRA et al., 2017).

A equidade constitui um dos princípios doutrinários do SUS e foi apresentada, a princípio, correlacionada à igualdade dos cidadáos perante o acesso às açôes e serviços. Posteriormente, o enfoque na igualdade dos cidadãos foi substituído pela ênfase na redução das disparidades sociais e regionais existentes no país. Contudo, estudos de base populacional dedicados a analisar características de desigualdades são escassos (ALBRECHT; ROSA; BORDIN, 2017; ANDRADE et al., 2017).

Em busca da efetivação dos princípios do SUS no cotidiano dos serviços, a ênfase da assistência recai na Atenção Primária à Saúde (APS), entre o conjunto de ações e serviços desenvolvidos pelo sistema, com a incorporação da Estratégia Saúde da Família (ESF) em 1994.

A expansão da ESF, em mais de duas décadas, tem favorecido a equidade e a universalidade da assistência. Entretanto, não se pode admitir, somente pelas estatísticas da expansão do número de equipes, que o acesso a uma assistência integral deixou de ser um problema no cotidiano dos serviços. (VIEGAS; PENNA, 2015, p. 238).

Desse modo, questiona-se: como os usuários compreendem a assistência à saúde, a equidade e a acessibilidade no cotidiano da APS perante os princípios e diretrizes do SUS? O estudo teve por objetivo responder a este questionamento. 


\section{Métodos}

Trata-se de estudo de abordagem qualitativa (MINAYO, 2010), descritivo, que utiliza como referencial metodológico o Estudo de Casos Múltiplos Holístico (YIN, 2015) e como referencial teórico a Sociologia Compreensiva do Cotidiano (MAFFESOLI, 2010).

O Estudo de Casos Múltiplos Holístico possibilita uma intensa análise do objeto de investigação, uma vez que cada caso representa uma única entidade, que é submetida a uma análise criteriosa e contínua de evidências convergentes ou divergentes com respeito aos fatos e às conclusóes para o caso (YIN, 2015). Já a Sociologia Compreensiva do Cotidiano possibilita a compreensão das experiências vividas, contextualizando as crenças e açôes das pessoas além dos sentimentos (MAFFESOLI, 2010), que, neste estudo, se dão em relação ao contexto de assistência à saúde, equidade e acessibilidade no cotidiano de usuários da APS perante os princípios e diretrizes do SUS.

O estudo integra dois casos definidos pelos cenários, sendo delimitados por dois municípios de duas microrregiôes sanitárias da Região Ampliada de Saúde Oeste de Minas Gerais: um município de grande porte populacional (238.230 habitantes e cobertura da ESF de 60,37\%) e um de pequeno porte populacional (10.547 habitantes e cobertura da ESF de 100\%). As unidades de saúde, para coleta de dados, foram determinadas de maneira aleatória por meio de sorteio, de forma equitativa, para unidades com equipes da ESF e unidades sem equipes da ESF, isto é, unidades de APS tradicionais. Compreenderam, no município de grande porte, três unidades de APS tradicionais e três unidades com equipes da ESF; e no de pequeno porte, uma APS tradicional e uma da ESF (Notas de campo). Os dois casos tiveram uma única unidade de análise: "a assistência à saúde, equidade e acessibilidade no SUS na voz do usuário da APS".

$\mathrm{O}$ município de pequeno porte é dividido em dois distritos. $\mathrm{O}$ atendimento da população é feito em quatro unidades de saúde, sendo três da ESF e uma da APS tradicional. As equipes da ESF são compostas por enfermeiro, técnico em enfermagem, médico, cirurgião-dentista, auxiliar de saúde bucal, agente comunitário de saúde (ACS). Essas equipes contam com uma equipe de apoio composta por terapeuta ocupacional, nutricionista, fonoaudióloga, ginecologista, pediatra e fisioterapeuta, que fazem atendimentos nas três unidades da ESF em dias diferentes da semana. $\mathrm{O}$ 
atendimento à população trabalhadora é realizado à noite em três unidades da ESF em dias alternados da semana. Em caso de atendimento por especialidades médicas (cirurgião-geral, neurologista, urologista, ortopedista, pediatra, ginecologista, obstetra e cardiologista), a população cadastrada pelas três equipes da ESF é encaminhada para a APS tradicional, localizada no centro da cidade (Notas de campo).

No município de grande porte, são contabilizados 64 estabelecimentos públicos de saúde, com prestação de serviços em: 11 Unidades de APS tradicional; 32 equipes da ESF; 1 policlínica; 1 unidade de pronto atendimento regional (UPA); 1 Centro de Atenção Psicossocial (CAPS), que conta com os serviços de urgência e emergência psiquiátrica, ambulatório psiquiátrico e 1 CAPS AD III; 7 farmácias para dispensação de medicamentos básicos; 1 Unidade de Vigilância em Saúde; 1 Central de Imunização; 1 Centro Regional de Reabilitação; 1 serviço especializado de odontologia; 3 serviços auxiliares de diagnose e terapia; 3 Unidades de Serviço de Atendimento Móvel de Urgência (SAMU). Outros estabelecimentos privados/ filantrópicos participam de forma complementar ao SUS, entre eles 3 hospitais e 16 serviços especializados (Notas de campo).

Os participantes deste estudo foram 77 usuários, dos quais 20 eram homens e 57, mulheres, com idade média de 41 anos. Quanto à escolaridade, a maioria tem ensino médio completo. Como critério de inclusão, estabeleceu-se ter no mínimo 18 anos e pessoas que possam responder por si. A abordagem dos participantes foi na Unidade de APS tradicional/ESF. Foram convidados os usuários que estavam presentes nos dias da coleta de dados, provenientes de demandas espontânea ou programática. $\mathrm{O}$ número de participantes não foi determinado a priori. Utilizou-se o critério de saturação que, neste estudo, foi por replicação literal, ou seja, quando se obteve um número suficiente de informações replicadas com resultados semelhantes (YIN, 2015). Contudo, sem desprezar as informaçóes novas e significativas que surgiram. Após perceber a saturação dos dados, foram realizadas cinco entrevistas para confirmar a replicação literal, confirmando o aparecimento de resultados similares nas entrevistas.

A coleta de dados teve como fontes de evidências a entrevista individual aberta com roteiro semiestruturado, a visita às unidades de saúde da APS tradicional e da ESF e registros em notas de campo. $\mathrm{O}$ roteiro continha perguntas relacionadas aos dados sociodemográficos dos participantes e nove perguntas abertas que responderiam à temática estudada. A coleta de dados ocorreu entre abril e setembro de 2017. A entrevista foi realizada em sala reservada, logo após a formalização do participante 
por meio do Termo de Consentimento Livre e Esclarecido. Foi gravada em áudio e, posteriormente, transcrita, e teve tempo médio de duraçáo de oito minutos. Obedeceu-se ao critério de saturação dos dados por replicaçâo literal (YIN, 2015). A saturação foi percebida no $72^{\circ}$ entrevistado e confirmada no $77^{\circ}$ participante, sendo então encerrada a coleta de dados.

Utilizou-se o referencial da Análise de Conteúdo Temática para análise dos dados, segundo as fases: pré-análise, exploração do material, tratamento dos resultados, inferência e interpretação (BARDIN, 2011). Os participantes do estudo foram identificados por códigos alfanuméricos simbolizados pela letra "E” (de entrevistado), seguido pelo número da entrevista do participante de forma sequencial, garantindo, portanto, o sigilo das informaçôes e o anonimato dos indivíduos.

A pesquisa foi desenvolvida segundo a Resolução do Conselho Nacional de Saúde $\mathrm{n}^{\circ}$ 466, de 12 de dezembro de 2012. A coleta de dados ocorreu após a aprovação do projeto pelo Comitê de Ética da Universidade Federal de São João del-Rei, sob o parecer $n^{\circ}$ 2.010.531. O estudo foi conduzido de acordo com as diretrizes do Consolidated Criteria for Reporting Qualitative Research (COREQ).

\section{Resultados}

A assistência à saúde e a acessibilidade às ações e serviços relacionam-se ao direito à saúde integral mediante acesso universal e equânime. O usuário, participante deste estudo, expressa sua noção sobre o SUS e a sua idealização; compreende a saúde como direito e dever do Estado, vinculada à expectativa de acessibilidade e qualidade da assistência, ao pagamento de impostos, mas declara as perdas no sistema devido ao subfinanciamento e aponta a corrupção:

Eu acho que o direito à saúde, todos têm, e a assistência todo mundo deveria ter. E o governo não tirar isso, pode estar ruim, pode ter as crises, mas náo tirar isso do ser humano (E47).

Eu pago por isso e teria que ter saúde não só para mim, mas para todo mundo. [...] esse é um direito do cidadáo, estamos perdendo o direito de tudo. Aí, a única coisa que você precisa, de saúde, até isso eles estão tirando da gente. [...] não adianta você colocar o melhor profissional do mundo e não dar condição de trabalho para ele trabalhar. É a mesma coisa de amarrar suas pernas e mandar você andar, isso é o SUS, você entendeu? (E50).

Aqui, você é muito bem atendido, mas é um descaso no resto do SUS, porque, muitas vezes, você tem que brigar muito para poder ter uma assistência, entendeu? Poderiam estar dando uma assistência melhor. SUS é assim, a gente paga por isso, não é de graça. É dever cuidar da gente. [...] mas é um plano de saúde invisível. Porque, na verdade, você 
paga mais imposto do que tem de pagar para um plano de saúde. O projeto SUS é ótimo, o que pega é o governo, que não dá assistência. O hospital público daqui acabou, por quê? Porque eles aproveitam para roubar ao invés de ajudar o povo, entendeu? [...] o hospital dá assistência à população do município e da região. E o que virou? Roubo! De quem? Dos grandes. Eles não pensam na saúde das pessoas. O SUS, em si, não é o problema. O que está matando o povo é a falta de assistência, porque não tem vaga (E50).

A (falta de) acessibilidade foi apresentada como a capacidade ou náo de obter a ação ou recurso necessário no momento do agravo, nos diferentes níveis de complexidade.

A agente comunitária de saúde vai na minha casa, sempre perguntando se está tudo bem. [...] Marca os exames e, se precisa de uma consulta, ela sempre marca. O atendimento é bom (E1).

Você não acha vaga, não acha atendimento. Tinha que ter uma organização, se você passar mal, tem que ir lá na UPA, porque aqui a marcação de consulta é só no dia 20, passou do dia 20, você não consegue consulta. Eu acho que tem que melhorar muito isso aí (E41).

Consigo ter acesso. Eu sou difícil de procurar aqui, porque, graças a Deus, eu não sou de vir ao médico [...]. Mas, todas as vezes que eu vim aqui, eles resolvem os meus problemas. [...] até dentista eles deram um jeitinho para mim (E8).

As dificuldades de acessibilidade foram associadas ao que os usuários vivenciam, concebem e atribuem ao SUS. Declaram a restrição do acesso a exames, medicamentos e atenção especializada:

Eu entendo que é um sistema bom, não é ótimo, claro que pelo fato do número de pessoas para atender, e isso depende nem tanto do sistema, mas do pessoal em si. Aqui é excelente [...]. mas eu já tive experiências horríveis, de mau atendimento e de pouco caso mesmo. Mas, aí, você leva em conta um monte de coisas, não é? Sei lá se a pessoa está com salário em dia, por exemplo, se estava tendo condições de trabalho ali (E46).

Eu sei que agora ficou ruim por causa da falta, igual, a gente vai nos postos e não tem remédio, eu entendo que tem muita gente aí que precisa.[...] ficou ruim por causa da corrupção [...] eu gastei seis anos para fazer esses óculos, a gente ganha pouco e não dá para fazer o que a gente quer [...] e quando chega na hora de você fazer um exame ou uma operação das veias, isso já faz quatro anos, acho que nem chega mais [...] então, eu acho que está faltando verba para ficar melhor, para não ficar tanto tempo esperando. [...] eu quero o encaminhamento para o ortopedista, e não tem. [...] a máquina de raio-X ficou fechada, quebrou, tem que ficar esperando, se for uma coisa de urgência, você tem que pagar, entendeu? (E2).

Quanto à farmácia, é só caminhada perdida, porque remédio, ultimamente, não tem, o que a gente faz? Tenho ido comprar. Exame, tem meses, não tem previsão [...] e eu preciso ter o raio X para eu ter o diagnóstico (E33).

Na parte de especialista, fica muito a desejar. [...] ultrassom, nunca consegui fazer" (E30). 
Às vezes, você está esperando uma ficha e tem alguém que está bem atrás de você que consegue pelo apadrinhamento [...] não acho justo (E9).

Igual eu, estou com um câncer no útero, eu preciso de uma cirurgia, mas sabe quando essa cirurgia vai sair? Um ano... daqui um ano, eu estarei viva? [...] são doenças que precisam de tempo rápido (E50).

Em meio aos obstáculos para utilização dos serviços, surge a compreensão de classificação de risco e da porta de entrada no sistema, considerando a equidade e as demandas sensíveis à APS:

De fato, existem algumas falhas, sim. O atendimento da UPA, a gente ouve falar bastante de reclamaçóes de pacientes que ficam horas... mas a gente sabe que até tem o outro lado, às vezes, a pessoa precisa, está sentindo alguma coisa que não é de UPA, e ela vai aguardar mais por causa da questão da prioridade. E aí, às vezes, ela fez a opção errada de ir para a UPA, sendo que ela devia ter procurado uma Unidade Básica de Saúde. Então, a pessoa não compreende qual é o atendimento de cada unidade, aí fica frustrada (E26).

O direito à saúde, para os participantes da pesquisa, vem atrelado à equidade no acesso, considerando a dimensão socioeconômica, a dificuldade de acesso ou inacessibilidade no momento da doença:

Ter direito à saúde é quando você está doente e está precisando daquele atendimento, precisando daquele exame e ter direito de fazê-lo, pode ter mil pessoas na fila, mas se precisa de uma atenção maior, eu acho que eles tinham que dar uma atenção maior, não é? Tem gente aqui no posto que não precisa, tem condiçóes de pagar um exame, aí eles tinham que dar preferência para um caso que é mais específico, não é pular na frente de uma vaga e tomar o lugar de pessoas que não têm (E6).

Eu acho que direito à saúde é muito profundo, isso é tão complicado! No Brasil? Difícil, não é? Difícil! Acho que abrange muita coisa! Direito à saúde é imprescindível, tinha que ser sem negociação, sem barganha, como acontece (E46).

A assistência à saúde frente aos desiguais é apresentada, na voz do usuário, como o único meio de atendimento para as pessoas em condiçóes de parcos recursos financeiros. A acessibilidade é enfatizada como resultados do SUS na vida de usuários:

Todas as vezes que eu vim aqui, fui bem atendida e resolveram meus problemas [...] bem, a gente está apoiado, porque, geralmente, não temos como pagar uma consulta particular, e sabendo que tem pelo SUS (E3).

Eu procuro o SUS, minha família inteira procura o SUS. [...] mas, a minha solução é o SUS, mas não tenho nada a reclamar, porque eu tenho assistência, mas eu corro atrás, porque, de braço cruzado, nada chega na minha porta não, é o correr, mesmo, atrás (E9).

“Teria que ter mais médicos à disposição, porque, hoje, há uma grande concorrência. E é o SUS que tem me dado muito resultado, graças a Deus (E9). 
No cotidiano, a assistência no SUS funciona, mas vem permeada pela morosidade do sistema:

Mas, no geral, o SUS funciona, sim. Só tem que ter paciência, porque, às vezes, demora, mas resolve. [...]. É lógico que se é um caso de internação, mas não tem vagas, aí a gente fica aguardando (E17).

A referência ao SUS vem acompanhada pela impossibilidade de se ter um plano de saúde e pela comparação da assistência no privado versus a assistência no SUS:

Como eu não tenho mais um plano de saúde, eu acho que o SUS é para ajudar a gente. Então, se não tivesse o SUS, como eu ia fazer? Se você chegar machucada, o SUS está ali para te atender, mesmo você tendo um plano de saúde, porque quando eu tinha o plano de saúde e precisava rápido, eu corria era para o SUS (E6).

A obrigação do SUS é atender a todos, e para quem não tem um plano de saúde, ele é o único. Mas, tem gente que prefere o plano... se não precisar do SUS, é melhor. Demora muito no SUS, se você for fazer uma cirurgia, os exames demoram; quando eles marcam o segundo exame, o primeiro já está quase vencendo os seis meses e só vale por seis meses, e você tem que renovar. Aí, eles gastam muito mais com a gente fazendo exame e repetindo (E12).

A assistência é diferenciada, não é? Por exemplo, se tiver um paciente que é do particular e você do SUS, ela é toda diferenciada. Seu quarto tem menos, para pior, não é? Os melhores quartos são para aqueles que pagam. Até no olhar você vê, na maneira de tratar, às vezes, acham que você não sabe de nada, não sabe nem de seu direito e os descasos mesmo que, às vezes, você encontra (E9).

O SUS é o único plano que todo cidadão devia ter (E25).

A maioria dos 77 participantes deste estudo (63 usuários) designa que o SUS é para os desiguais, referindo-se aos que estão em carência econômica:

O SUS é para pessoa que não tem uma renda boa, não tem plano de saúde, aí tem que procurar o SUS (E53).

Olha, eu acho que o SUS é para as pessoas que não conseguem ter um plano de saúde (E33).

É o amparo do governo para as pessoas carentes (E39).

Eu entendo que o SUS é aquele que trata de quem não tem dinheiro. Mesmo quem tem dinheiro ainda vai no SUS, mas quem não tem, o único apoio que tem é o SUS (E44).

A carência de recursos do usuário desempregado e a do sistema o leva ao amparo em Deus, na esperança de conseguir assistência:

Está ruim. Igual meu filho, precisa de um exame porque ele está com um sério problema de vista; eu tenho renda pequena, não tenho condições de pagar a consulta dele e tenho que esperar na fila com todas as outras pessoas, fazer o quê? Eu tenho que pegar na mão de Deus e esperar. Porque eu estou sem trabalho, está difícil mesmo, aí ou eu pago o 
aluguel ou eu vou dar preferência para os óculos dele. Vou conversar com a moça onde eu moro, eu pago aluguel todo mês certinho, mas vou ter que pagar os óculos e talvez a consulta dele (E6).

Nos momentos de espera na recepção das unidades para aguardar a oportunidade de abordar o usuário, e com a permissão para entrevistá-lo, foi observado que havia muitos usuários na sala de espera em demanda espontânea em algumas unidades. Quase sempre, a espera e o desejo eram pelo atendimento médico. Observou-se, também, uma desorganização administrativa nas unidades de saúde, o que levava, algumas vezes, a conflitos entre usuários e a equipe, situaçôes como a longa espera pelo atendimento e para marcaçóes de consultas e exames (notas de campo).

\section{Discussão}

Com seus mais de 30 anos de existência, o SUS ainda pode ser considerado um processo social em construção. Talvez, em parte, pela ambiçáo de seu projeto, como também pela dificuldade de se estabelecer uma política pública em território tão extenso, em consonância com as desigualdades regionais e atribuladas questôes políticas. Vale ressaltar a necessidade de um financiamento adequado para seu êxito, pois observa-se que esse sistema sofre de subfinanciamento crônico ao longo de suas três décadas (FREITAS; ARAÚJO, 2018).

A saúde pública brasileira, desde a sua concepção, transparece a dificuldade das esferas de governo em se organizarem. Essa dificuldade se evidencia pela competição entre os Poderes, que, em certos momentos, está condensada na esfera federal, com um controle das instituições estatais no território, e, em outros momentos, com a vigência da esfera estadual apresentando iniciativas locais (PESSOTO; RIBEIRO; GUIMARÁES, 2015). Ao chegar à terceira década do "SUS, vive-se um período de grave perturbação da ordem política, social, moral” (SANTOS, 2018, p. 2.044).

Assim, ainda persiste uma dificuldade de acessibilidade, um problema a ser superado pelo sistema. É de suma importância ressaltar que o direito à saúde, na concepção adotada pela Assembleia Geral das Naçóes Unidas em 1966 (BRASIL, 1992), prevê o desfrute de saúde física e mental por todas as pessoas nas suas respectivas integralidade e necessidade. Desta forma, a saúde deve ser garantida por meio do acesso facilitado aos serviços de saúde, construído por um sistema de cuidados acessível (FAJARDO-DOLCI; GUTIÉRREZ; GARCÍA-SAISÓ, 2015; GARCIA, 2018). 
Os participantes desta pesquisa restringem a acessibilidade aos serviços e açóes no SUS de forma direta, mas o seu caráter público abrange indiretamente toda a população brasileira em ações de vigilância à saúde, epidemiológica, sanitária, ambiental, do trabalhador, nos procedimentos de alto custo, fornecimento de medicamentos especiais, imunizaçôes, "em inúmeras açôes de cunho preventivo e de promoção da saúde. Sem SUS, é barbárie sanitária” (SANTOS, 2018, p. 2.049).

Entre as demandas apontadas pelos usuários, ainda se enfrenta dificuldade de acessibilidade a exames e às açôes de média complexidade, especialmente às consultas com especialidades médicas. Um estudo, realizado em um município da Regiáo Metropolitana de Belo Horizonte, MG, corrobora esse resultado ao identificar "que a grande demanda por atendimento especializado foi associada à pouca resolutividade dos médicos da APS, à demora na marcação de consultas, à falta de especialistas e dificuldades na regulação do sistema de saúde municipal” (VIEGAS; CARMO; LUZ, 2015, p. 107).

Essa dificuldade também é refletida em outros lugares, como na província de Quebec, Canadá. Para as pessoas que vivem em situação de pobreza, o acesso a cuidados especializados (por exemplo, fisioterapia, psicoterapia, nutrição) é considerado problemático, pois para consultar o sistema público de saúde da província de Quebec, Canadá, o tempo de espera é de mais de um ano (LOIGNON et al., 2015).

As dificuldades de acesso aos serviços sugerem baixa resolutividade das demandas e, consequentemente, culminam em uma visão negativa dos usuários participantes deste estudo sobre o serviço de saúde. Uma pesquisa realizada com 840 famílias em comunidades urbanas, periurbanas e rurais no norte da Nigéria mostrou que 50,4\% dos entrevistados classificaram os serviços de saúde como ruins. $\mathrm{O}$ fator que mais contribui para essa visão negativa do usuário foi o fato de não ter acesso a alguns medicamentos no momento da necessidade (ONYENEHO et al., 2016).

Todavia, percebem-se, nas falas de alguns usuários, vários fatores que geram a satisfação em relação ao serviço de saúde, Entre eles destacam-se aqueles relacionados à gratuidade dos serviços, ao bom relacionamento com os profissionais, à resolutividade clínica, ao acesso aos medicamentos e ao encaminhamento de consultas. É muito presente nas falas do usuário a satisfação ao ter acesso e resolutividade de uma demanda, especialmente, por terem a concepção de que o serviço é gratuito. Nota-se que a gratuidade dos serviços náo é percebida como um direito de cidadania e que contribuem para ter esse direito. Ilustram, com isso, a noção de consumidores de um 
bem com resolutividade sem relacionar ao direito de acesso universal e integral. É o viver cotidiano na saúde que, apesar das dificuldades para o atendimento, se projeta para a subjetividade, conferindo o que Maffesoli traz: "a sociedade não é apenas um sistema mecânico de relaçóes econômico-políticas ou sociais, mas um conjunto de relações interativas, feito de afetos, emoções, sensações que constituem, stricto sensu, o corpo social” (MAFFESOLI, 1996 p. 73), conferindo a satisfação do ser usuário, mesmo em luta para superação das dificuldades de acessibilidade.

Além disso, a divulgação em mídias sobre a ineficiência da atenção prestada pelo sistema público é de forma não representativa de todas as açôes. Geralmente, é focada em um caso isolado, contribui para a construção de um senso comum coletivo que tem uma visão extremamente negativa sobre os serviços e a qualidade do SUS (QUEVEDO et al., 2016). Assim, "ser atento aos mistérios do ser é reconhecer o que, nos fenômenos sociais, elabora-se aquém ou além da simples consciência racional" (MAFFESOLI, 2007, p. 67); é considerar as experiências cotidianas exitosas, isoladas e coletivas, que se fazem presentes nos serviços e na vida dos usuários e dar maior visibilidade ao sistema como valor social em um país de extremas desigualdades.

Em relação à equidade, muito presente nas falas dos participantes deste estudo, não é exclusiva do sistema de saúde brasileiro, é resultado presente em pesquisas de outras realidades, como na América Latina e no Caribe, ao evidenciar a equidade na atenção à saúde das mulheres. Os resultados apontaram uma desvantagem em relação ao acesso aos serviços por parte de mulheres menos favorecidas economicamente, das indígenas e negras (JACQUES et al., 2017).

Um estudo que apresenta um retrato do desempenho do sistema de saúde em seis países de renda média - que, em sua totalidade, respondem por mais da metade da população mundial - encontrou falhas em vários indicadores, particularmente nos domínios de eficácia, custo e equidade (ALSHAMSAN et al., 2017).

Já quanto ao fato de a APS ser a porta de entrada prioritária do SUS, uma pesquisa realizada em cinco regióes de saúde, das cinco macrorregióes brasileiras, evidenciou o seguinte: em relação à porta de entrada preferencial para a Rede de Atenção à Saúde, os gerentes das unidades de APS são quase unânimes em afirmar que é a APS. Por outro lado, quando questionados sobre a contribuição da APS na resolutividade dos problemas de saúde, em média, 52,5\% afirmam contribuição positiva, sendo que em duas regióes esse percentual cai para 33\%. A gestâo da APS tem contribuído para a melhoria do fluxo assistencial e para a integração dos serviços da Rede. Ao avaliar 
o agendamento em tempo oportuno, de exames e consultas com especialistas, a prestação do serviço/assistência em tempo adequado, de acordo com a necessidade do usuário, tem como fim evitar complicaçôes, o que é fundamental no controle de doenças, especialmente crônicas. Isso se traduz em uso racional e eficiente dos recursos em saúde, com alocação apropriada, o que, por consequência, reduz gastos desnecessários (BOUSQUAT et al., 2019). Concluiu-se que "ainda prevalece a visão da APS como locus de busca e acesso a procedimentos simples, como medicamentos ou aferição da pressão arterial. Esse perfil é encontrado, inclusive, entre usuários frequentes dos serviços" (BOUSQUAT et al., 2019, p. 10).

Os resultados deste estudo também trazem a cultura da assistência à saúde frente ao adoecimento e à busca pelo atendimento médico. Um estudo realizado no sul do Brasil mostrou que a população está habituada ao modelo de atenção centrado na doença, que se mostra pela busca constante de usuários por medicamentos e resolução imediata do problema, ou seja, não há perspectiva de prevenção de agravos e promoção da saúde. É necessário, portanto, um maior esforço no âmbito de todo o sistema para superação do modelo médico hegemônico e, sobretudo, responsabilização de todos os profissionais da área pela atenção à saúde interdisciplinar e resolutiva (BARATIERI et al., 2017).

Este estudo aponta as dificuldades na relação profissional versus usuário. Esses dados são corroborados por uma pesquisa realizada em Montes Claros, Minas Gerias, Brasil, com 2.150 participantes. Desses, somente 36,3\% tinham plano de saúde. $\mathrm{O}$ estudo demonstrou que, em relação à assistência nos serviços públicos de saúde, a maioria dos participantes $(64,2 \%)$ manifestou algum desagrado com os profissionais/serviços; dificuldades para marcar consultas, principalmente com especialistas, além de exames; dificuldade de acesso ao local de assistência devido a condiçôes geográficas; e morosidade no atendimento (DIAS et al., 2016).

Embora a maior parte, $82 \%$ dos entrevistados deste estudo, acredite que o SUS é para aqueles em carência econômica, é importante ressaltar que o sistema abrange toda a população, pois ele é responsável pela articulação e coordenação das ações de promoção da saúde, bem como prevenção de riscos e agravos, além do diagnóstico, tratamento e reabilitação. Ademais, o SUS não desenvolve somente açôes relacionadas à assistência à saúde, mas ressalta a vigilância sanitária, a vigilância epidemiológica, a vacinação, dentre outras. Ou seja, toda a populaçáo é 
assistida pelo SUS, mesmo os usuários, que, na assistência, preferem recorrer aos planos de saúde (FREITAS; ARAÚJO, 2018).

Destaca-se que a vigilância em saúde ao alcance de todos os brasileiros visa à promoção e proteção da saúde da população por meio de planejamento e implementação de medidas de políticas públicas. A vigilância em saúde é acionada, também, em situaçóes incomuns, como epidemias, caracterizando emergências de saúde pública, visando a respostas rápidas e eficazes para a proteção da saúde da população e da diminuição de riscos e danos (TEIXEIRA et al., 2018).

O SUS é a potência da massa brasileira para impulsionar a participação na manutenção e controle da saúde individual e coletiva. Busca-se pelo desenvolvimento humano e qualidade de vida, isto é, o bem viver. Para Maffesoli, o bem viver é uma proposta atual (MAFFESOLI, 2010; MAFFESOLI, 2007).

\section{Conclusões}

Embora existam várias dificuldades que ainda persistem no SUS, em seus mais de 30 anos, como as relacionadas à acessibilidade equânime dos usuários à atenção integral, pelo sistema foi possível a inclusão universal ao direito social à saúde. Entretanto, superar as inúmeras fragilidades é decisivo para o aprimoramento de um sistema universal e, consequentemente, uma APS mais abrangente, coordenadora do cuidado e ordenadora da Rede de Atenção à Saúde. Todavia, a APS ainda enfrenta dificuldades para efetivamente ser uma porta preferencial de entrada nas realidades estudadas. A assistência e as condiçóes estruturais da APS encontram limites. Em relação à concepção do usuário, a assistência à saúde e a acessibilidade são relacionadas a um direito social instituído, mas encontram entraves ao buscar por esse direito, especialmente no que concerne ao acesso a exames e consultas com especialistas.

Em face ao exposto, o presente manuscrito apresenta relevância para a saúde coletiva e avança ao contribuir sobremaneira para a compreensão de como a efetivaçáo do direito à saúde se mostra no cotidiano de brasileiros no contexto da APS das realidades estudadas, que, apesar de terem características locais diferenciadas, apresentam resultados similares. Esses resultados servem de subsídio para formulação de estratégias e açôes para ampliação da acessibilidade e construir uma saúde pública mais justa, com valor e princípio da equidade como fator redutor de desigualdades. 
A limitação deste estudo se deve ao fato de a coleta de dados ter sido realizada apenas no cenário da APS, muito embora os participantes relatem suas vivências em outros níveis de atenção. Mas são necessários outros estudos que abordem os demais níveis de complexidade.

No cotidiano, é preciso valorizar os grandes avanços do SUS, além de acreditar no sistema e participar efetivamente para êxito em seu contínuo processo de construção e enfrentamento dos problemas que perduram. Embora os participantes deste estudo tenham a visão do sistema com o foco de atenção direta à saúde, o SUS tem cobertura universal e indistinta para todos os brasileiros em serviços de vigilância sanitária de alimentos e medicamentos, de vigilância epidemiológica, de sangue e hemoderivados, de transplante de órgãos, imunizações, dentre outros. Além disso, a ESF, pela extensão e cobertura, tem sido considerada um paradigma a ser seguido por outros países. É preciso participar e continuar a construçáo da universalidade do direito à saúde integral e equânime sem distinções e restrições. ${ }^{1}$

\section{Agradecimento}

À Fundação de Amparo à Pesquisa do Estado de Minas Gerais, pelo financiamento da pesquisa que originou este artigo (Edital 003/2016/PIBIC/Fapemig).

\section{Referências}

ALBRECHT, C. A. M.; ROSA, R. DOS S.; BORDIN, R. O conceito de equidade na produção científica em saúde: Uma revisão. Saúde e Sociedade, v. 26, n. 1, p. 1-10, 2017. Disponível em: http://dx.doi.org/10.1590/s0104-12902017162684

ALSHAMSAN, R. et al. Comparative health system performance in six middle-income countries: cross-sectional analysis using World Health Organization study of global ageing and health. Journal of the Royal Society of Medicine, v. 110, n. 9, p. 365-375, 2017. Disponível em: http://dx.doi.org/10.1177/0141076817724599.

ANDRADE, M. V. et al. Family health strategy and equity in prenatal care: A population based cross-sectional study in Minas Gerais, Brazil. International Journal for Equity in Health, v. 16, n. 1, p. 1-10, 2017. Disponível em: http://dx.doi.org/10.1186/s12939-016-0503-9

BARATIERI, T. et al. Percepçôes de usuários atendidos em um pronto atendimento: olhar sobre a atenção primária à saúde. Espaço para a Saúde - Revista de Saúde Pública do Paraná, v. 18, n. 1, p. 54, 2017. Disponível em: http://dx.doi.org 10.5433/15177130-2017v18n1p54 
BARDIN L. Análise de conteúdo. Tradução de Luís Antero Reto, Augusto Pinheiro. São Paulo: Edições 70, 2011.

BRASIL. Senado Federal. Constituição da República Federativa do Brasil. Brasília: Senado Federal, 1988.

BRASIL. Decreto $n^{\circ}$ 591, de 6 de julho de 1992. Atos Internacionais. Pacto Internacional sobre Direitos Econômicos, Sociais e Culturais. Promulgação. 1992. Disponível em: http://www. planalto.gov.br/ccivil_03/decreto/1990-1994/d0591.htm

BOUSQUAT, A. et al. Iniquities in the built environment related to physical activity in public school neighborhoods in Curitiba, Paraná State, Brazil. Cadernos de Saude Pública, v. 35, p. 1-16, 2019. Disponível em: http://dx.doi.org/10.1590/0102-311x00099118

DIAS, O. V. et al. Acesso às consultas médicas nos serviços públicos de saúde Material e Métodos Trata-se de estudo transversal, analítico e de base populacional. Rev Bras Med Fam Comunidade, v. 11, n. 38, p. 1-13, 2016. Disponível em: https://doi.org/10.5712/rbmfc11(38)1185

FAJARDO-DOLCI, G.; GUTIÉRREZ, J. P.; GARCÍA-SAISÓ, S. Acceso efectivo a los servicios de salud: Operacionalizando la cobertura universal en salud. Salud Publica de Mexico, v. 57, n. 2, p. 180-186, 2015. Disponível em: http://dx.doi.org/10.21149/spm.v57i2.7415

FREITAS, M. A. S; ARAÚJO, M. R. N. As Redes de Atenção à Saúde nos 30 anos do Sistema Único de Saúde: histórias, propostas e desafios. Revista Brasileira de Políticas Públicas, v. 8, n. 3, 2018. Disponível em: http://dx.doi.org/10.5102/rbpp.v8i3.5739

GARCIA, R. Expanding the debate: Citizen participation for the implementation of the right to health in Brazil. Health and Human Rights, v. 20, n. 1, p. 163-172, 2018. Disponível em: https://www.ncbi.nlm.nih.gov/pubmed/30008560

JACQUES, N. et al. Equidade na atenção à saúde de mulheres no Haiti. Revista Panamericana de Salud Pública, v. 41, p. 1, 2017. Disponível em: https://doi.org/10.26633/RPSP.2017.34

LOIGNON, C. et al. Perceived barriers to healthcare for persons living in poverty in Quebec, Canada: The EQUIhealThY project. International Journal for Equity in Health, v. 14, n. 1, p. 14-19, 2015. Disponível em: http://dx.doi.org/10.1186/s12939-015-0135-5

MAFFESOLI, M. Le réenchantement du monde: une éthique pour notre temps. Paris: Éditions de La Table Ronde, 2007. . No fundo das aparências. Petrópolis-RJ: Vozes, 1996.

. O conhecimento comum: introdução à sociologia compreensiva. Traduzido por Aluizio Ramos Trinta. Porto Alegre: Sulina, 2010. 295 p.

MINAYO, M. C. S. Los conceptos estructurantes de La investigación cualitativa. Salud colectiva, v. 6, n. 3, p. 251-261, 2010. Disponível em: https://pesquisa.bvsalud.org/portal/ resource/pt/lil-596634 
ONYENEHO, N. G. et al. Perception and utilization of public health services in Southeast Nigeria: Implication for health care in communities with different degrees of urbanization. International Journal for Equity in Health, v. 15, n. 1, p. 1-11, 2016. Disponível em: http://dx.doi. org/10.1186/s12939-016-0294-z

OLIVEIRA, A. P. C. et al. Challenges for ensuring availability and accessibility toin health care services under Brazil's unified health system (SUS). Ciencia e Saude Coletiva, v. 22, n. 4, p. 1165-1180, 2017. Disponível em: http://dx.doi.org/10.1590/1413-81232017224.31382016

PESSOTO, U. C.; RIBEIRO, E. A. W.; GUIMARÃES, R. B. O papel do Estado nas políticas públicas de saúde: Um panorama sobre o debate do conceito de estado e o caso Brasileiro. Saude e Sociedade, v. 24, n. 1, p. 9-22, 2015. Disponível em: http://dx.doi.org/10.1590/S010412902015000100001

QUEVEDO, A. et al. Direito à saúde, acesso e integralidade: análise a partir de uma unidade de saúde da família. Revista de APS, v. 19, n. 1, p. 47-57, 2016. Disponível em: https://periodicos. ufjf.br/index.php/aps/article/view/15640

SANTOS, L. SUS-30 anos: um balanço incômodo? Ciência e saúde coletiva, v. 23, n. 6, p. $2043-$ 2050, 2018. Disponível em: https://doi.org/10.1590/1413-81232018236.06082018.

TEIXEIRA, M. G. et al. Vigilância em Saúde no SUS - construçáo, efeitos e perspectivas. Ciência e saúde colet. v. 23, n. 6. 2018. Disponível em: https://doi.org/10.1590/141381232018236.09032018

VIEGAS, A. P. B.; CARMO, R. F.; DA LUZ, Z. M. P. Fatores que influenciam o acesso aos serviços de saúde na visão de profissionais e usuários de uma unidade básica de referência. Saude e Sociedade, v. 24, n. 1, p. 100-112, 2015. p. 107. Available from: http://dx.doi.org/10.1590/ S0104-12902015000100008

VIEGAS, S. M. F.; PENNA, C. M. M. Integrality: Life principle and right to health. Investigacion y Educacion en Enfermeria, v. 33, n. 2, p. 237-247, 2015. p. 238. Disponível em: http://dx.doi.org/10.17533/udea.iee.v33n2a06

YIN, R. K. Estudo de caso: planejamento e métodos. Tradução de Cristhian Matheus Herrera. 5. ed. Porto Alegre: Bookman, 2015. 290 p.

\section{Nota}

${ }^{1}$ L. C. do Nascimento, C. Menezes, G. R. Roquini e T. R. Santos: coleta e interpretação dos dados, participação na discussão dos resultados, redação do artigo. S. M. da F. Viegas: concepção e delineamento do trabalho, coleta e interpretação dos dados, participação na discussão dos resultados, revisão crítica do conteúdo, aprovação da versão final do artigo. 


\section{Abstract}

SUS in the lives of Brazilians: care, accessibility, and equity in the daily life of Primary Health Care users

Objective: To understand health care, equity and accessibility in the daily lives of Primary Health Care (PHC) users. Methodology: This is a qualitative and descriptive study, outlined by the Holistic Multiple Case Study method and by the theoretical framework of Comprehensive Sociology of Everyday Life, in which 77 SUS (Unified Health System) users from two municipalities in Minas Gerais, Brazil, participated. Results: Express the user's notion about SUS, its idealization, the reality experienced considering accessibility and care in PHC, relating them to the right to health. Conclusions: PHC still faces difficulties to be the preferred gateway to the studied realities. There are structural limits in the PHC to achieve comprehensive care in a network. Overcoming difficulties and limits is central to strengthening the SUS.

> Keywords: health services accessibility; health care delivery; health equity; Primary Health Care; Unified Health System. 